\title{
Effect of annealing temperature on different physical properties of $\mathrm{Sr}_{0.5} \mathrm{La}_{0.5} \mathrm{Mg}_{0.5} \mathrm{Fe}_{11.5} \mathrm{O}_{19}$ hexaferrite
}

\author{
Bilal Hamid Bhat* and Basharat Ahmad Want \\ SSRL, Department of Physics, University of Kashmir, Hazratbal Srinagar-190006 \\ *Email: hamid.bilal767@gmail.com
}

M-type Hexaferrites are the typical magnetic materials used in different technological application such as microwave electronics, magnetic memories [1, 2] and, biological applications [3]. The influence of annealing on different physical properties of $\mathrm{La}_{0.5} \mathrm{Mg}_{0.5} \mathrm{Sr}_{0.5} \mathrm{Fe}_{11.5} \mathrm{O}_{19}$ hexaferrites prepared by the citrate-precursor method (Figure 1) is presented in this study. The effects of temperature on the physical properties of the synthesized hexaferrites have been investigated using X-ray diffraction (XRD), Fourier transform infrared spectroscopy (FTIR), Scanning Electron Microscopy (SEM), and Vibrating Sample Magnetometer (VSM). The XRD study shows the formation of hexagonal structure with grain size lying between 23.86 $\mathrm{nm}$ and $56.12 \mathrm{~nm}$. FTIR was used to study functional groups associated with the material (Figure 2). A decrease in saturation magnetization $\left(\mathrm{M}_{\mathrm{s}}\right)$, and increase in Coercivity $\left(\mathrm{H}_{\mathrm{C}}\right)$ is observed with increase in temperature. Also, anisotropy constant was calculated by using Law of Approach to saturation and is well agreement with the literature.

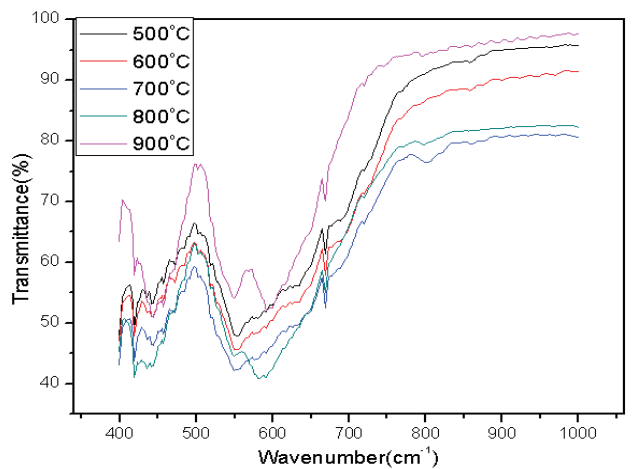

Figure 2: $\quad$ FTIR of $\quad \mathrm{La}_{0.5} \mathrm{Mg}_{0.5} \mathrm{Sr}_{0.5} \mathrm{Fe}_{11.5} \mathrm{O}_{19}$ hexaferrites

\section{References}

1. Hu F., Garcia L. F., Liu X. S., Zhu D. R., Suarez M., Menendez J. L. , J. Appl. Phy (2011), 109, 11309.

2. Shirtcliffe N. J., Thompson S., O'Keefe E. S., Appleton S., Perry C .C., Mater Res Bull, (2007), 42 281 .

3. Safarik I., Safarikova M ., Monatshefte Fur Chemie (2002), 133,737.

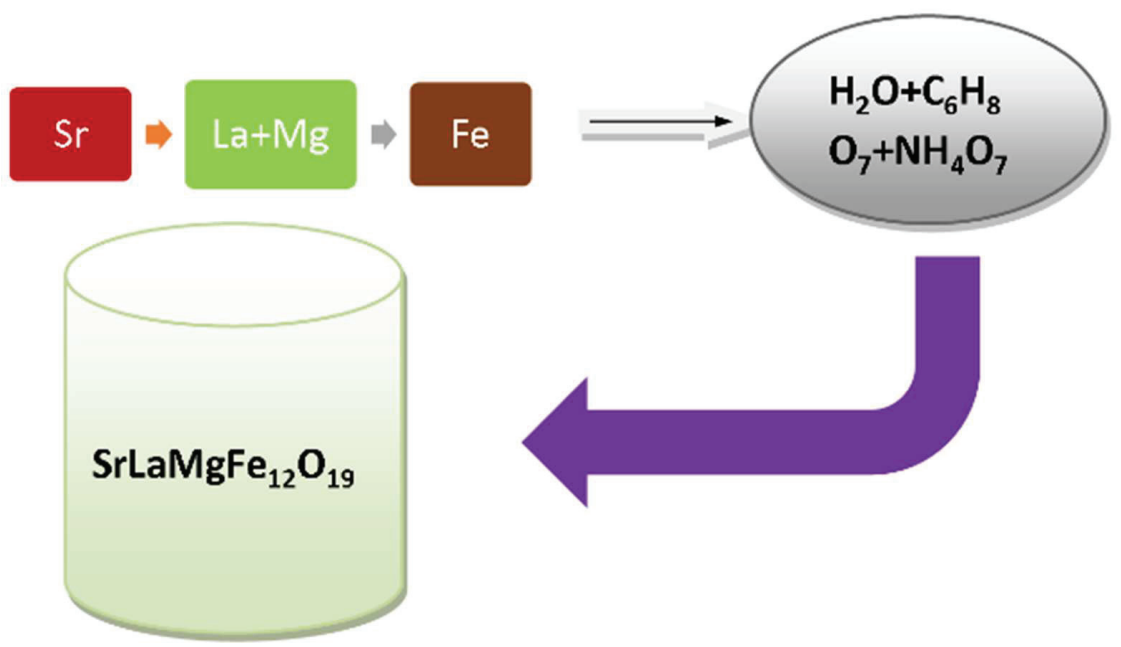

Figure 1: Preparation of $\mathrm{La}_{0.5} \mathrm{Mg}_{0.5} \mathrm{Sr}_{0.5} \mathrm{Fe}_{11.5} \mathrm{O}_{19}$ hexaferrites 